OPEN ACCESS

Edited by:

Jiarui Wu,

Beijing University of Chinese

Medicine, China

Reviewed by:

Hongyong Deng,

Shanghai University of Traditional

Chinese Medicine, China

Xinfeng Guo,

Guangzhou University of Chinese

Medicine, China

*Correspondence:

Dongran Han

handongr@gmail.com

YeXia

xiaye.whu@outlook.com

${ }^{\dagger}$ These authors have contributed equally to this work

Specialty section:

This article was submitted to

Clinical Diabetes,

a section of the journal

Frontiers in Endocrinology

Received: 21 January 2021

Accepted: 23 March 2021

Published: 20 April 2021

Citation:

Li Y, Miao R, Liu Y, Zhang J, Dou Z,

Zhao L, Zhang $Y$, Huang $Z$, Xia $Y$ and

Han D (2021) Efficacy and Safety of

Tripterygium Glycoside in the

Treatment of Diabetic Nephropathy: A

Systematic Review and Meta-Analysis Based on the Duration of Medication.

Front. Endocrinol. 12:656621.

doi: 10.3389/fendo.2021.656621

\section{Efficacy and Safety of Tripterygium Glycoside in the Treatment of Diabetic Nephropathy: A Systematic Review and Meta-Analysis Based on the Duration of Medication}

\author{
Yizhen $\mathrm{Li}^{1+}$, Runpei Miao ${ }^{2 \dagger}$, Yixing Liu ${ }^{3}$, Jiawei Zhang ${ }^{1}$, Zhili Dou ${ }^{1}$, Lei Zhao ${ }^{1}$, \\ Yunan Zhang ${ }^{1}$, Zhe Huang ${ }^{1}$, Ye Xia ${ }^{1 *}$ and Dongran Han ${ }^{1 *}$ \\ ${ }^{1}$ School of Life and Science, Beijing University of Chinese Medicine, Beijing, China, ${ }^{2}$ School of Traditional Chinese Medicine, \\ Beijing University of Chinese Medicine, Beijing, China, ${ }^{3}$ School of Management, Beijing University of Chinese Medicine, \\ Beijing, China
}

Aim: The aim of this study was to assess the clinical efficacy and safety of Tripterygiumderived glycosides (TG) after 3-month and 6-month of treatments of diabetic nephropathy (DN) and to resolve the conflict between medicine guidance and clinical practice for TG application.

Methods: We conducted a systematic review and meta-analysis of randomized controlled trials involving TG application in treating DN. We extensively searched PubMed, Cochrane Library, CNKI, VIP, Wan-Fang, CBM, Chinese Clinical Trial Registry, and WHO International Clinical Trial Registration Platform till November 2020, along with grey literature for diabetes and all other relevant publications to gather eligible studies. Based on the preset inclusion and exclusion criteria, document screening, quality assessment of methodology, and data extraction was conducted by two researchers independently. The methodological quality was assessed by the Cochrane risk test from the Cochrane Handbook 5.2, and then analyses were performed by Review Manager 5.3 (Rev Man 5.3). The quality of output evidence was classified by GRADE.

Results: Thirty-one eligible studies (2764 patients) were included for this meta-analysis. Our study results showed a comparable significant decrease in the $24 \mathrm{~h}-$ UTP and blood creatinine levels in DN patients from both 3-month and 6-month TG treatment groups, compared with the routine symptomatic treatment alone. To the contrary of the findings from the included studies, our results showed that the occurrence of serious adverse reaction events was significantly higher in the TG treated group with 6 months of treatment duration compared to that of 3 months of the treatment course. However, the total AR ratio was slightly varied while increasing the percent of severe adverse events. GRADE assessment indicated that the quality of evidence investigating TG-induced adverse reactions was moderate and that for $24 \mathrm{~h}$-UTP and blood creatinine indicators were considerably low. 
Conclusion: Combinatorial treatment regimen including TG can significantly decrease the pathological indicators for DN progression, while it can also simultaneously predispose the patient to a higher risk for developing severe adverse events, as the medicine guidance indicates. Notably, even in 3-month of course duration smaller percent of severe adverse events can get to a fatal high percent and is likely to increase proportionally as the TG treatment continues. This suggests that TG-mediated DN treatment duration should be optimized to even less than 3 continuous months to avoid adverse event onsetassociated further medical complications in DN patients. In clinical practice, serious attention should be paid to these severe side-effects even in a course normally considered safe, and importantly more high-quality studies are urgently warranted to obtain detailed insights into the balance between the efficacy and safety profiles of TG application in treating DN.

Keywords: tripterygium glycosides, meta-analysis, systematic review, diabetic nephropathy, medication safety

\section{INTRODUCTION}

Diabetic nephropathy (DN) is characterized by degeneration of the renal microvasculature leading to leakage of proteins like albumin into the urine (commonly known as proteinuria), perturbed glomerular filtration, increased fluid retention, and high arterial blood pressure (1). DN frequently occurs in patients with diabetes mellitus, and its symptoms indicate chronic endstage renal failure. $\mathrm{DN}$ is also considered as the leading cause of death in patients with chronic renal failure, with a prevalence rate of $4.8 \%(1,2)$. Current therapeutic regimens include angiotensin II receptor blocker (ARB) and inhibitors for angiotensin-converting enzyme (ACE) to reduce the high blood pressure-associated renal complications and progression to DN $(3,4)$. Although some studies claim that ARBs are effective in treating proteinuria or albuminuria than $\mathrm{ACE}$ inhibitors, however, there are also contradictory results showing both of them have very similar efficacy in reducing proteinuria symptoms in primary hypertensive patients $(5,6)$. Despite the routine clinical applications of these drugs for slowing down DN progression, it has been challenging to reduce proteinuria completely in both diabetic- and non-diabetic patients with DN, particularly in cases of severe proteinuria. Furthermore, $\mathrm{ARB} / \mathrm{ACE}$ inhibitors can induce fatal side-effects in patients with advanced stages of chronic renal insufficiency and having a serum creatinine level greater than $3 \mathrm{mg} / \mathrm{dL}$ (7).

Hyper-activation of inflammatory responses has been frequently observed in patients with diabetes-related renal dysfunctions or chronic renal insufficiency (8), which further complicates the pathogenesis of DN $(9-11)$. Recent investigations have greatly explored effective strategies for inhibition of renal infiltration of activated immune cells, cytokine storm, inflammatory responses, apoptosis, and podocyte injury as well to prevent DN progression $(9,12,13)$. Notably, recently developed reno-protective drugs, such as sodium-glucose cotransporter-2 (SGLT-2) inhibitors, also have shown promising anti-inflammatory and anti-oxidative stress effects in the treatment of DN (14).
Tripterygium glycosides (TG) is an active compound found in the root extracts of Tripterygium wilfordii (TW). TG has been an essential component of traditional Chinese medicine for the treatment of glomerulonephritis and as a powerful immunosuppressive agent during kidney transplantation. TG has been increasingly utilized in the treatment of DN mainly due to its anti-inflammatory functions as well as its superb ability to prevent oxidation-induced membrane disruption in the glomerulus, thereby preventing DN progression and proteinuria (15-17). Moreover, combined therapy, including TG and ARB/ACE inhibitors, have been clinically applied as a potential therapeutic regimen against DN symptoms $(18,19)$.

In spite of multimodal pharmaceutical benefits of TG in treating several chronic life-threatening diseases, including DN and rheumatoid arthritis, TG-induced adverse events (AEs) have been mostly found to be systemic, organ-specific depending on the drug dose and duration of medication course (20). According to the drug overdose-related guidelines for TG tablets (Hunan Xieli Pharmaceutical Co. Ltd. National Medicine Standard Z43020138), long-term administration of TG may impact a number of physiological functions, e.g., digestion, blood pressure, renal and cardiovascular dysfunctions as TG-induced AEs, thus recommending a safe dose and course duration for 3 months. However, several other groups have shown no significant differences in safety profiles between 3 months and 6 months of treatment duration (21). Furthermore, recent studies investigating the impacts of different doses of TG in treating DN has revealed that $60 \mathrm{mg} /$ day of TG is more effective than $30 \mathrm{mg} /$ day for a period of 6 months with the same safety profile (22), and also TG is more efficient than valsartan in reducing the proteinuria level (23). The study also reports that there was no significant difference in $\mathrm{AE}$ occurrences between the placebo-treated and low-dose TG treated groups; however, in the double-dose group, only one patient exhibited an elevated level of alanine aminotransferase but was less than 2-fold compared to the baseline level, which was immediately normalized after symptomatic treatment.

Controversies exist between systematic reviews that focus on the clinical efficacy and adverse reactions of TG in the treatment 
of DN. Some researchers believe that TG can improve some clinical indicators of patients with DN, such as 24 h-UTP and serum creatinine level (24-26), while others reached negative conclusions that TG can significantly induce adverse reactions in patients with $\mathrm{DN}(27,28)$, and even questioned whether TG can be used to reduce the serum creatinine level of patients (28).

Thus, in this meta-analysis and systematic literature review regarding the safety and efficacy of TG administration in DN treatment and its relation to the duration of medication course, we have investigated the immediate necessities for "how" and "when" to balance between the standard medicine usage guidelines and empirical therapies for TG. This study will be highly beneficial to lay the theoretical foundations and practical clinical applications of TG to cure DN.

\section{MATERIALS AND METHODS}

\section{Methods}

This meta-analysis was conducted following the guidelines of the Preferred Reporting Items for Systematic Reviews and MetaAnalysis (PRISMA). Prior ethics approval and consent of the participants were not required for this study since it involved only previously published RCT studies.

\section{Literature Search Strategy}

We performed a systematic search on PubMed, Cochrane Library, and WHO International Clinical Trial Registration Platform (ICTRP) for English language publications and China National Knowledge Internet (CNKI), China Science \& Technology Journal Database (VIP), Wan-Fang digital periodical full-text database, Chinese Biomedical Literature Database (CBM) and Chinese Clinical Trial Registry (ChiCTR) for Chinese publications from database inception to November 05, 2020 based on the defined inclusion and exclusion criteria. The predefined English terms used for the search included "diabetic nephropathy" or "diabetic kidney disease" and "tripterygium glycosides" and terms related to randomized controlled trials (RCTs). In addition, we searched both manually and electronically for potentially eligible abstracts of newspapers, grey literature in the field of diabetes, along with any associated e-magazine references in order to prevent from missing any relevant studies. All the literature was published before November 2020. The detailed search strategy is provided in the supporting information.

\section{Selection Criteria}

Relevant studies were carefully screened by abstracts and titles, and then the eligibility criteria were applied based on PICOS as follows: (1) Patients: patients diagnosed with DN. The diagnostic criteria of DN was in accordance with 2007 National Kidney Foundation Kidney of Disease Outcomes Quality Initiative (NKF-K/DOQI): That is, in most patients with diabetes, the kidney damage should be considered as caused by diabetes if any of the following conditions occurs: massive proteinuria, diabetic retinopathy with microalbuminuria, microalbuminuria occurs in type 1 diabetes with the course of diabetes lasting for more than 10 years. (2) Intervention: TG combined with basic treatment applied, and the duration of TG treatment lasted for 3 or 6 months. (3) Comparison: TG combined with the basic treatment comparing with the basic treatment. (4) Outcomes: The efficacy of primary outcome was assessed by the changes in $24 \mathrm{~h}$-urine total protein (24 h-UTP) and blood creatinine levels. (5) Study design: randomized controlled trials (RCTs) that applied TG in conventional treatment for DN for 3 months or 6 months of course duration, regardless of English or Chinese language, year of publication or country of publication.

Records retrieved from electronic searches were imported into reference management software (EndNote X7, Thomson Reuters, New York, NY, USA). After removing duplicate records, two reviewers independently screened the titles and abstracts of the remaining reports and subsequently investigated potentially eligible studies in full text. Inclusion and exclusion criteria are presented in Table S1. Differences in opinion between the two independent reviewers at any stage of the study processes were resolved by their mutual consensus or were further arbitrated by a third reviewer to reach a consensus.

\section{Data Extraction and Risk-of-Bias Assessment}

Two researchers extracted data independently, any discrepancies were discussed and resolved after consulted with a senior researcher. For each eligible trial, data on study characteristics, participants' baseline characteristics, key efficacy, and safety outcomes were extracted.

The risk of bias for the primary outcome was assessed by the respective tool developed by the Cochrane Collaboration 5.2. In this assessment, the following domains were considered: random sequence generation, allocation concealment, blinding of participants and personnel, blinding of outcome assessment, incomplete outcome data, selective reporting, and other biases. The risk of bias for every domain was rated as high, unclear or low independently. Key domains included random sequence generation, allocation concealment, and incomplete outcome data. Publication bias was tested by funnel plot symmetry when at least 10 studies were available per meta-analysis.

\section{Data Synthesis and Statistical Analysis}

The extracted data were analyzed separately for 3-month treatment or 6-month treatment durations. We used the relative risk (RR) with 95\% confidence intervals (CI) for dichotomous data, mean difference (MD) with 95\% CI for continuous outcomes, heterogeneity quantified as high with $\mathrm{I}^{2}$ values $>50 \%$ and $p<0.1$. If substantial heterogeneity existed, a random-effects model was used to pool measures; otherwise, a fixed-effects model was used. Statistical analyses were performed using RevMan 5.3 (Nordic Cochrane Center, Copenhagen, Denmark, 2014).

\section{RESULTS}

\section{Search Results and Study Characteristics}

The study selection process is depicted in Figure 1. A total of 31 studies with 2764 participants were included after careful 


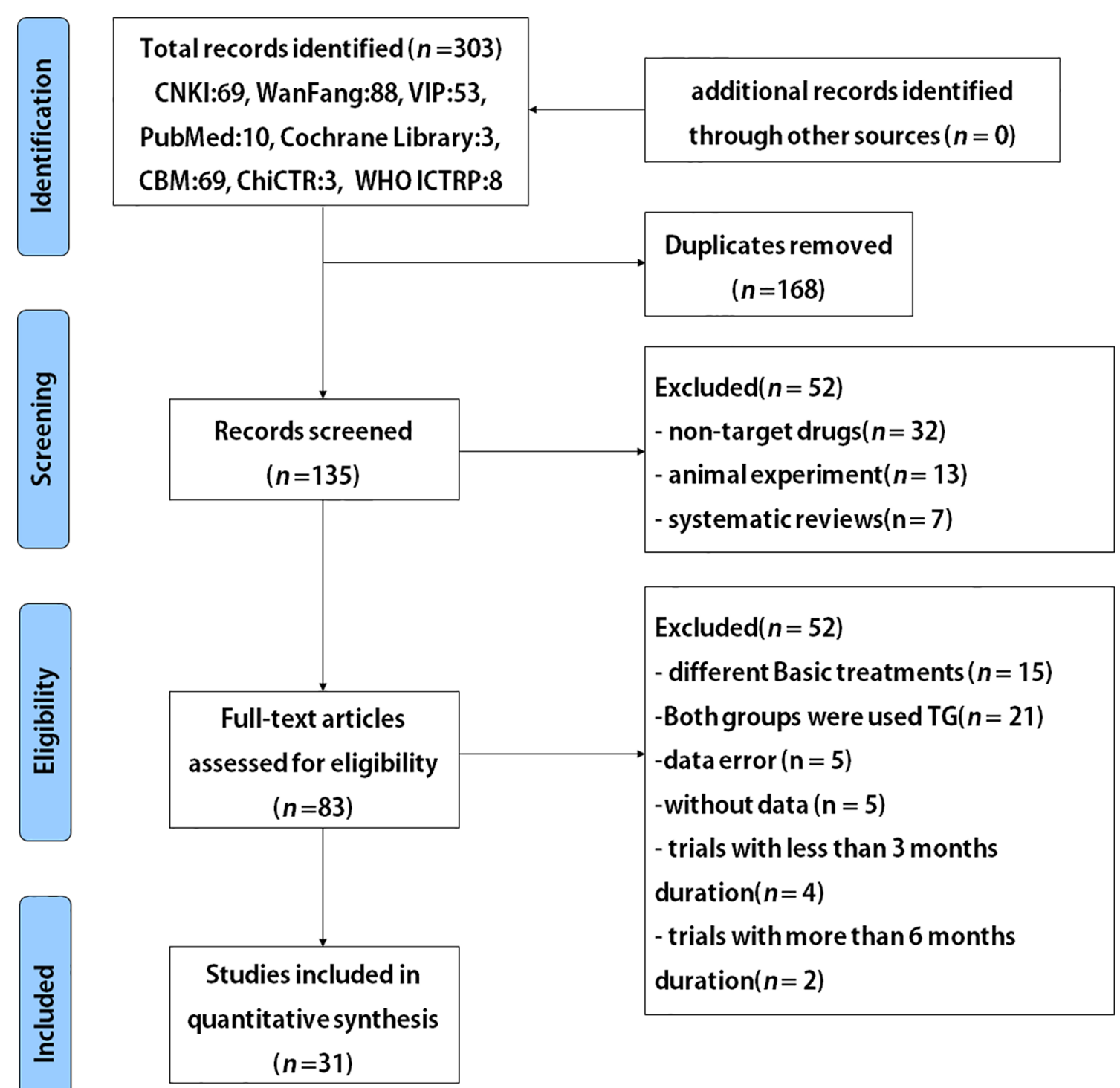

FIGURE 1 | Flowchart for randomized controlled trials (RCTs) to evaluate the use of TG after 3 and 6 months of treatment durations in patients with DN.

screening and evaluation for the systematic review $(22,29-58)$ (Table 1). All the studies were published in full-text, and participants' characteristics are shown in Table 1. The mean ages across the studies were ranged from 34.6 to 69.5 years, and $46.9 \%$ (1295) of the overall participants were women. Courses of treatment included were 3 months and 6 months. In all included trials TG combined with routine symptomatic treatments were compared with the symptomatic treatments alone. The symptomatic treatment targets included control of blood pressure and blood sugar, reduction of urinary protein content and blood creatinine level, etc. All studies exhibited that the baseline results for the TG-treated group and the corresponding control group were comparable.

\section{Results With a Duration of 3-Month Treatment}

\section{Risk-of-Bias Assessment}

Risk-of-bias assessment is shown in Figure S1. 24 h-UTP, blood creatinine, and AE outcome indicators were evaluated separately by the funnel plot, which revealed that no asymmetry existed in AEs, but significant publication bias was found for $24 \mathrm{~h}$-UTP and blood creatinine (Figures S2-4).

\section{4 h-UTP}

Fourteen studies $(29,31-33,38-47)$ including 1120 participants reported that the $24 \mathrm{~h}$-UTP levels were significantly reduced [MD $-0.30 ; 95 \%$ confidence interval $(\mathrm{CI}):-0.35$ to -0.25 ; 
TABLE 1 | Characteristics of studies and participants included in systematic review and meta-analysis.

\begin{tabular}{|c|c|c|c|c|c|}
\hline Study, year [reference] & $\begin{array}{l}\text { Number of } \\
\text { participants }\end{array}$ & Dose of TG & Study duration, months & Outcomes of $24 \mathrm{~h}-$ UTP and blood creatinine & Adverse event report \\
\hline Li et al., 2012 (29) & 128 & $60 \mathrm{mg} / \mathrm{d}$ & 3 & 24h-UTP & Not reported \\
\hline Lu et al. 2020 (30) & 100 & $60 \mathrm{mg} / \mathrm{d}$ & 3 & Not reported & YES \\
\hline Wang et al. 2013 (31) & 64 & - & 3 & 24h-UTP, blood creatinine & YES \\
\hline Gai et al. 2020 (32) & 104 & $60 \mathrm{mg} / \mathrm{d}$ & 3 & 24h-UTP, blood creatinine & No adverse event \\
\hline Zhu et al. 2018 (33) & 180 & $1 \mathrm{mg} /(\mathrm{kg} \cdot \mathrm{d})$ & 3 & 24h-UTP, blood creatinine & YES \\
\hline Wang et al., 2017 (34) & 60 & $60 \mathrm{mg} / \mathrm{d}$ & 3 & Not reported & YES \\
\hline Sun et al., 2019 (35) & 100 & $1 \mathrm{mg} /(\mathrm{kg} \cdot \mathrm{d})$ & 3 & blood creatinine & YES \\
\hline Yan et al., 2017 (36) & 92 & $60 \mathrm{mg} / \mathrm{d}$ & 3 & Not reported & No adverse event \\
\hline Liu et al., 2015 (37) & 60 & $1 \mathrm{mg} /(\mathrm{kg} \cdot \mathrm{d})$ & 3 & blood creatinine & YES \\
\hline Wang et al., 2018 (38) & 80 & $60 \mathrm{mg} / \mathrm{d}$ & 3 & 24h-UTP & No adverse event \\
\hline Liu et al., 2015 (39) & 40 & $1 \mathrm{mg} /(\mathrm{kg} \cdot \mathrm{d})$ & 3 & 24h-UTP & YES \\
\hline Zhang et al., 2015 (40) & 40 & $1 \mathrm{mg} /(\mathrm{kg} \cdot \mathrm{d})$ & 3 & 24h-UTP, blood creatinine & No adverse event \\
\hline Shen et al., 2011 (41) & 90 & $1 \mathrm{mg} /(\mathrm{kg} \cdot \mathrm{d})$ & 3 & 24h-UTP, blood creatinine & YES \\
\hline Shi et al., 2018 (42) & 81 & $60 \mathrm{mg} / \mathrm{d}$ & 3 & 24h-UTP, blood creatinine & YES \\
\hline Sun et al., 2012 (43) & 60 & $30-60 \mathrm{mg} / \mathrm{d}$ & 3 & 24h-UTP, blood creatinine & YES \\
\hline Shen et al., 2011 (44) & 30 & $60 \mathrm{mg} / \mathrm{d}$ & 3 & 24h-UTP & YES \\
\hline Hao et al., 2017 (45) & 58 & $120 \mathrm{mg} / \mathrm{d}$ & 3 & 24h-UTP, blood creatinine & YES \\
\hline Li et al., 2018 (46) & 62 & $1-1.5 \mathrm{mg} /(\mathrm{kg} \cdot \mathrm{d})$ & 3 & 24h-UTP, blood creatinine & No adverse event \\
\hline Ma et al., 2020 (47) & 102 & $60 \mathrm{mg} / \mathrm{d}$ & 3 & 24h-UTP, blood creatinine & YES \\
\hline Wang et al.2018 (22) & 40 & $60 \mathrm{mg} / \mathrm{d}$ & 6 & 24h-UTP, blood creatinine & YES \\
\hline Kong et al., 2013 (48) & 60 & $60 \mathrm{mg} / \mathrm{d}$ & 6 & 24h-UTP, blood creatinine & YES \\
\hline Lu et al., 2019 (49) & 200 & $30-60 \mathrm{mg} / \mathrm{d}$ & 6 & Not reported & YES \\
\hline Yu et al., 2011 (50) & 129 & $60 \mathrm{mg} / \mathrm{d}$ & 6 & 24h-UTP, blood creatinine & YES \\
\hline Yang et al., 2013 (51) & 60 & $1-1.5 \mathrm{mg} /(\mathrm{kg} \cdot \mathrm{d})$ & 6 & Not reported & YES \\
\hline Li et al., 2020 (52) & 80 & $10-60 \mathrm{mg} / \mathrm{d}$ & 6 & 24h-UTP, blood creatinine & YES \\
\hline Zhou et al., 2019 (53) & 200 & $30-60 \mathrm{mg} / \mathrm{d}$ & 6 & 24h-UTP, blood creatinine & Not reported \\
\hline Xu et al., 2017 (54) & 72 & $10-60 \mathrm{mg} / \mathrm{d}$ & 6 & blood creatinine & YES \\
\hline Gao et al., 2012 (55) & 80 & $60 \mathrm{mg} / \mathrm{d}$ & 6 & 24h-UTP, blood creatinine & YES \\
\hline Chen et al., 2009 (56) & 119 & $1-2 \mathrm{mg} /(\mathrm{kg} \cdot \mathrm{d})$ & 6 & 24h-UTP, blood creatinine & YES \\
\hline Shan et al., 2013 (57) & 70 & $1 \mathrm{mg} /(\mathrm{kg} \cdot \mathrm{d})$ & 6 & Not reported & YES \\
\hline Zhou et al., 2019 (58) & 122 & $10-60 \mathrm{mg} / \mathrm{d}$ & 6 & Not reported & YES \\
\hline
\end{tabular}

$\left.\mathrm{I}^{2}=98 \%\right]$ after 3-month of combined TG treatment compared with the non-TG regular treatment alone (Figure 2).

A subgroup analysis was conducted to reduce the heterogeneity in the results. The studies were divided into 4 subgroups (group 1: range $>3$ g, group 2: range $2.8-3$ g, group 3 : range 1.8-2.8 g, group 4: range $0.2-1.5 \mathrm{~g}$ ) according to the baseline level of $24 \mathrm{~h}$-UTP. The results showed that heterogeneity was reduced in the first three subgroups (Figure 3), suggesting that the difference in the $24 \mathrm{~h}$-UTP baseline level was one of the critical heterogeneity sources. However, group 4 still had significant heterogeneity $\left(\mathrm{I}^{2}=98 \%\right)$, which might be due to the limited number of available full-text literatures that could not be further categorized, resulting in the substantial variation at the baseline level of group 4 than other groups.

\section{Blood Creatinine}

12 studies (31-33, 35, 37, 40-43, 45-47) including 1002 participants reported that the blood creatinine levels were significantly decreased [MD - 12.63; 95\% CI: -21.96 to -3.31 ; $\left.\mathrm{I}^{2}=98 \%\right]$ after 3-month of combined TG treatment compared with the non-TG regular treatment alone. (Figure 4).

A similar subgroup analysis was conducted to reduce the heterogeneity in the results. Likewise, studies were divided into 3 subgroups according to the baseline level of blood creatinine (group 1: range 160-200 $\mu \mathrm{mol} / \mathrm{L}$, group 2: range $99-130 \mu \mathrm{mol} / \mathrm{L}$, group 3: range $60-92 \mu \mathrm{mol} / \mathrm{L})$. In the first two subgroups, the heterogeneity was reduced to an acceptable degree, but in the third subgroup, high heterogeneity was still existed (Figure 5). A post hoc sensitivity analysis was conducted to explore the heterogeneity origin in the third subgroup results. Notably, exclusion of a trial reported by Li (2018) (46)reduced the heterogeneity to a comparable level with respect to other subgroups [MD in blood creatinine -1.56 ; 95\% CI: -2.92 to $\left.0.20 ; \mathrm{I}^{2}=0 \%\right]$, suggesting that the difference in the blood creatinine baseline level of the patients was the main source of heterogeneity in this meta-analysis.

\section{Adverse Reactions}

Adverse reaction events were reported in 13 studies (29, 30, 3234, 36, 38, 40-44, 47), including 1148 subjects after 3-month of combined treatment with TG, which significantly increased the adverse reaction events [MD 2.02; 95\% CI: 1.35 to 3.00; $\mathrm{I}^{2}=0 \%$ ], compared with non-TG regular treatments (Figure 6). This data was inconsistent with the findings of the included clinical studies involving TG administration that $\mathrm{TG}$ could not induce significant AEs even after 3 months of continuous treatment duration.

In addition, the AEs related to the treatments combined with TG mainly reflected symptoms of leukopenia and abnormal liver functions (Table 2). 


\begin{tabular}{|c|c|c|c|c|c|c|c|c|c|c|c|}
\hline \multirow[b]{2}{*}{ Study or Subgroup } & \multicolumn{3}{|c|}{ Experimental } & \multicolumn{2}{|c|}{ Control } & \multirow[b]{2}{*}{ Total } & \multirow{2}{*}{\multicolumn{2}{|c|}{$\begin{array}{ll} & \text { Mean Difference } \\
\text { Weight } & \text { IV. Random. } 95 \% \mathrm{Cl}\end{array}$}} & \multirow{2}{*}{\multicolumn{2}{|c|}{$\begin{array}{c}\text { Mean Difference } \\
\text { IV.Random, } 95 \% \mathrm{Cl}\end{array}$}} & \\
\hline & Mean & SD & Total & Mean & SD & & & & & & \\
\hline Gai2020 & 0.14937 & 0.01216 & 52 & 0.19725 & 0.01508 & 52 & $21.2 \%$ & $-0.05[-0.05,-0.04]$ & 4 & & \\
\hline Hao2017 & 2.03 & 1.38 & 29 & 2.85 & 1.25 & 29 & $0.5 \%$ & $-0.82[-1.50,-0.14]$ & & & \\
\hline Li2012 & 0.1852 & 0.0213 & 64 & 0.3428 & 0.0294 & 64 & $21.1 \%$ & $-0.16[-0.17,-0.15]$ & - & & \\
\hline Li2018 & 0.05205 & 0.00711 & 31 & 0.14655 & 0.00847 & 31 & $21.2 \%$ & $-0.09[-0.10,-0.09]$ & I & & \\
\hline LIU2015 & 1.2 & 0.3 & 20 & 1.6 & 0.4 & 20 & $4.1 \%$ & $-0.40[-0.62,-0.18]$ & - & & \\
\hline Ma2020 & 0.8 & 0.21 & 51 & 1.09 & 0.5 & 51 & $7.3 \%$ & $-0.29[-0.44,-0.14]$ & - & & \\
\hline SHEN2011 & 1.1 & 0.8 & 45 & 1.9 & 0.9 & 45 & $1.8 \%$ & $-0.80[-1.15,-0.45]$ & - & & \\
\hline Shen2011 & 1.2 & 2.2 & 15 & 3 & 2.1 & 15 & $0.1 \%$ & $-1.80[-3.34,-0.26]$ & 一 & & \\
\hline Shi2018 & 0.73 & 0.33 & 41 & 1.37 & 0.24 & 41 & $9.1 \%$ & $-0.64[-0.76,-0.52]$ & $=$ & & \\
\hline Sun2012 & 2.72 & 1.5 & 30 & 4.39 & 1.66 & 30 & $0.4 \%$ & $-1.67[-2.47,-0.87]$ & & & \\
\hline Wang2013 & 0.62 & 0.43 & 32 & 1.27 & 0.63 & 32 & $3.0 \%$ & $-0.65[-0.91,-0.39]$ & - & & \\
\hline Wang2018 & 1.93 & 0.36 & 40 & 2.94 & 0.46 & 40 & $5.6 \%$ & $-1.01[-1.19,-0.83]$ & - & & \\
\hline Zhang2015 & 1.93 & 1.28 & 20 & 2.73 & 1.36 & 20 & $0.4 \%$ & $-0.80[-1.62,0.02]$ & & & \\
\hline Zhu2018 & 1 & 0.7 & 90 & 1.8 & 0.8 & 90 & $4.1 \%$ & $-0.80[-1.02,-0.58]$ & $r$ & & \\
\hline Total $(95 \% \mathrm{Cl})$ & & & 560 & & & 560 & $100.0 \%$ & $-0.30[-0.35,-0.25]$ & 1 & & \\
\hline \multicolumn{9}{|c|}{$\begin{array}{l}\text { Heterogeneity: } \operatorname{Tau}^{2}=0.00 ; \mathrm{Chi}^{2}=759.12, \mathrm{df}=13(\mathrm{P}<0.00001) ; \mathrm{I}^{2}=98 \% \\
\text { Test for overall effect: } Z=11.76(P<0.00001)\end{array}$} & $\begin{array}{ccc}-4 & -2 & 0 \\
\text { Favours [experimental] }\end{array}$ & $\begin{array}{c}2 \\
\text { Favours [control] }\end{array}$ & 4 \\
\hline
\end{tabular}

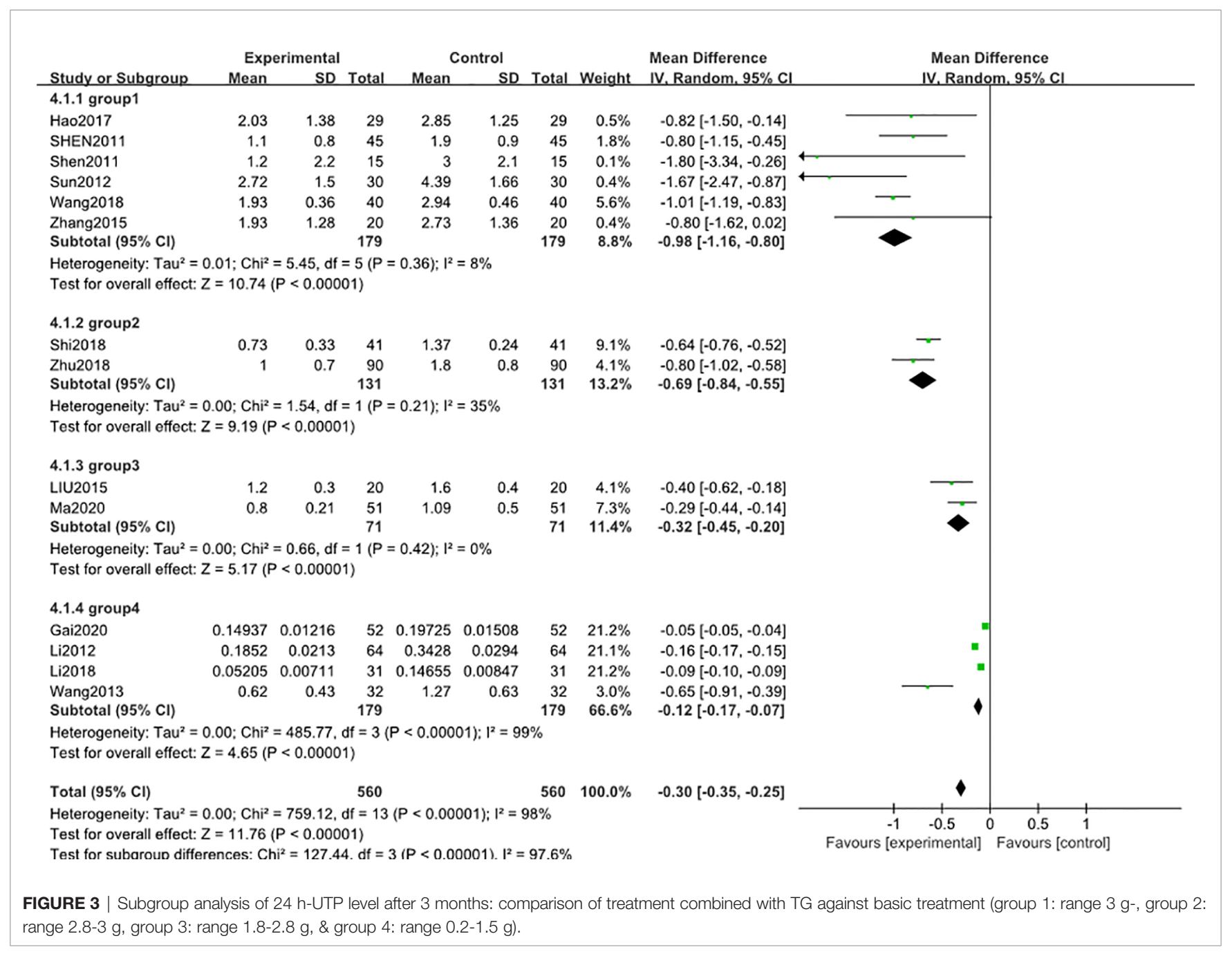




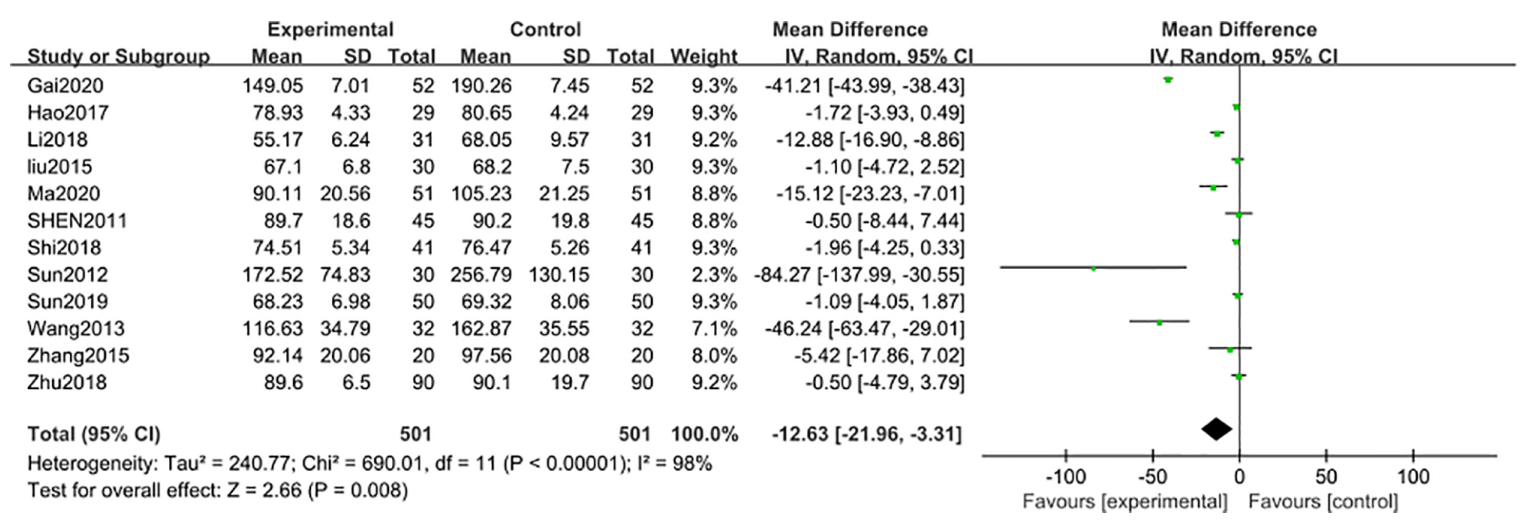

FIGURE 4 | Blood creatinine level after 3 months: comparison of treatment combined with TG against basic treatment.

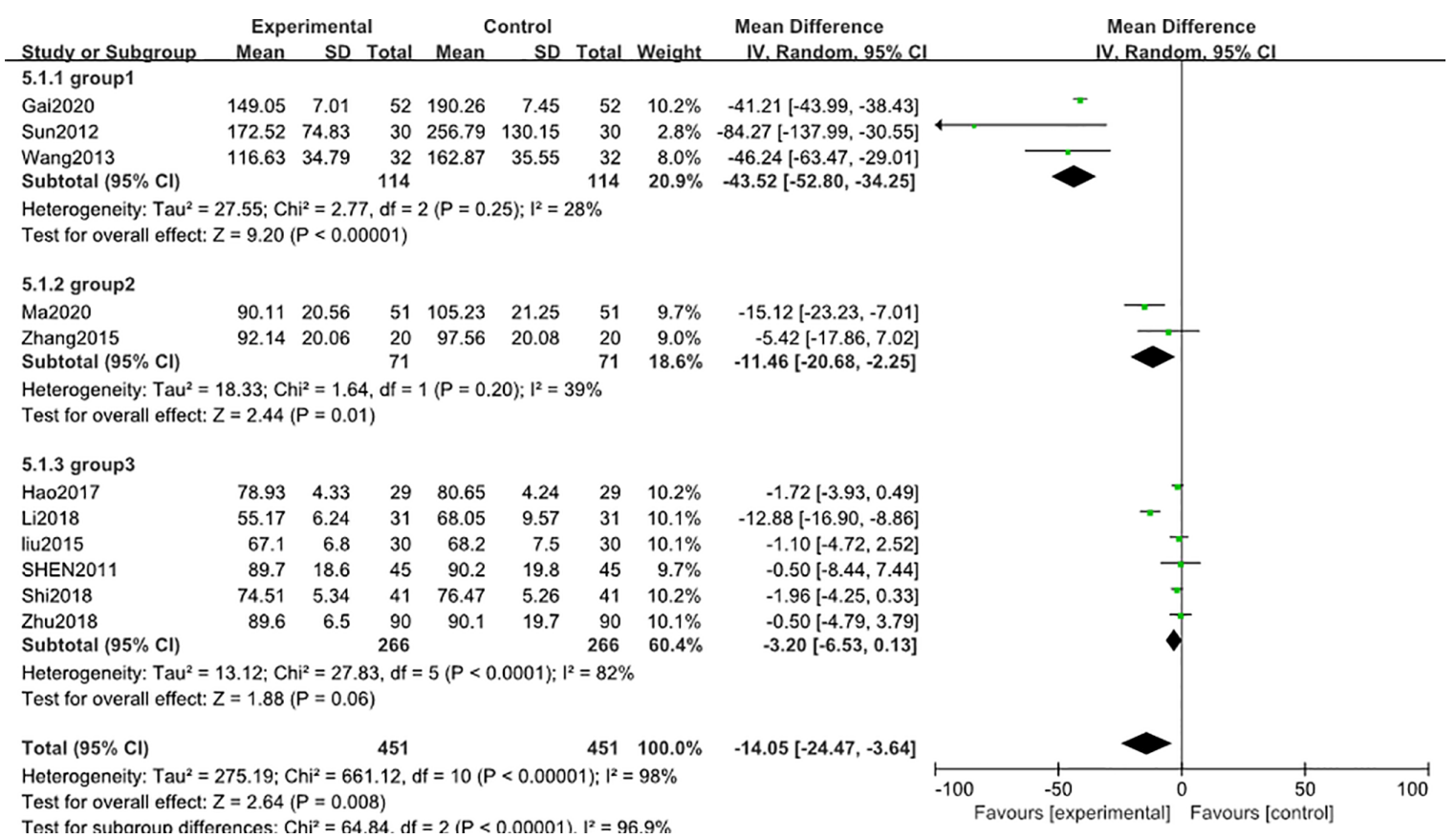

FIGURE 5 | Subgroup analysis of blood creatinine level after 3 months: comparison of treatment combined with TG against basic treatment (group 1: range 160$200 \mu \mathrm{mol} / \mathrm{L}$, group 2: range $99-130 \mu \mathrm{mol} / \mathrm{L}$, group 3: range $60-92 \mu \mathrm{mol} / \mathrm{L})$.

\section{Results With a Duration of 6-Month Treatment \\ Risk-of-Bias Assessment}

The risk-of-bias assessment is shown in Figure S5. The adverse reaction outcome indicators were evaluated by the funnel plot, which showed no asymmetry (Figure S6).

\section{4 h-UTP}

7 studies $(22,48,50,52,55,56,58)$ including 708 participants reported that the $24 \mathrm{~h}$-UTP after 6-month of treatment combined with TG was significantly reduced [MD $-0.91 ; 95 \% \mathrm{CI}:-1.27$ to $-0.56 ; \mathrm{I}^{2}=92 \%$ ] (Figure 7).

A subgroup analysis was conducted to reduce obvious heterogeneity. The studies were divided into 2 subgroups (group 1: range 2-3 g, group 2: range 4-5 g), according to the baseline level of $24 \mathrm{~h}$-UTP. However, subgroup 1 still exhibited significant heterogeneity $\left(\mathrm{I}^{2}=81 \%\right)$, while subgroup 2 involved only one article, thus could not be analyzed for heterogeneity. To explore the heterogeneity in subgroup 1, a post hoc sensitivity analysis was conducted, resulting in the exclusion of a trial reported by Kong et al. (48), thereby reducing the 


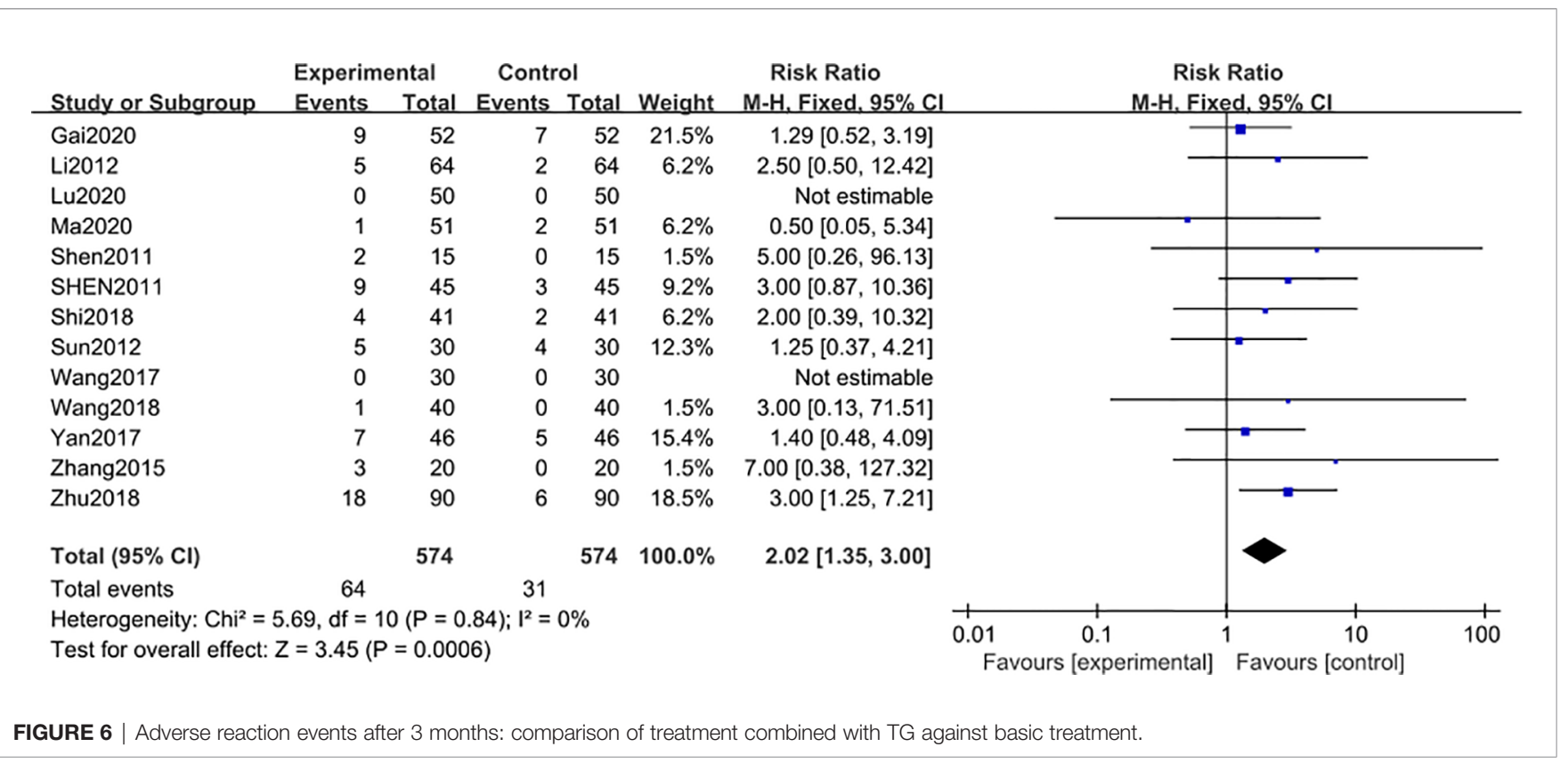

TABLE 2 | Statistics of adverse reaction events after 3-month treatment.

\begin{tabular}{lcc}
\hline $\begin{array}{l}\text { adverse } \\
\text { reactionevents }\end{array}$ & $\begin{array}{c}\text { treatment combined with } \\
\text { TGtotal (574 patients) }\end{array}$ & $\begin{array}{c}\text { basic treatmenttotal } \\
\text { (574 patients) }\end{array}$ \\
\hline $\begin{array}{l}\text { gastrointestinal } \\
\text { reactions }\end{array}$ & $29(5.1 \%)$ & $25(4.4 \%)$ \\
leukopenia & $17(3.0 \%)^{*}$ & $0(0.0 \%)$ \\
$\begin{array}{l}\text { abnormal liver } \\
\text { function } \\
\text { hypotension }\end{array}$ & $14(2.4 \%)^{*}$ & $0(0.0 \%)$ \\
$\begin{array}{l}\text { hyperkalemia } \\
\text { fatigue }\end{array}$ & $2(0.3 \%)$ & $4(0.7 \%)$ \\
elevated & $1(0.2 \%)$ & $0(0.0 \%)$ \\
creatinine & $1(0.2 \%)$ & $0(0.0 \%)$ \\
dizziness & $0(0.0 \%)$ & $1(0.2 \%)$ \\
total & $0(0.0 \%)$ & $1(0.2 \%)$ \\
& $64(11.2 \%)$ & $31(5.5 \%)$
\end{tabular}

${ }^{*} p<0.01$ (compared with basic treatment). heterogeneity [MD $-0.62 ; 95 \% \mathrm{CI}:-0.77$ to $-0.47 ; \mathrm{I}^{2}=42 \%$ ] (Figure 8), suggesting that the difference in the $24 \mathrm{~h}$-UTP baseline was the main source of heterogeneity, as was observed for 3-month treatment duration.

\section{Blood Creatinine}

8 studies $(47,48,50,52,54-56,58)$ including 780 participants reported that blood creatinine level was reduced after 6-month of treatment combined with TG [MD -2.85; 95\% CI: -5.03 to $\left.-0.68 \% ; \mathrm{I}^{2}=87 \%\right]$, compared with the non-TG regular treatment (Figure 9). Similar subgroup analysis was used to reduce the heterogeneity to an acceptable degree after dividing the articles into two groups (group 1: range $70-88 \mu \mathrm{mol} / \mathrm{L}$, group 2: range $94-109 \mu \mathrm{mol} / \mathrm{L}$ ) (Figure 10), and the results showed that the heterogeneity was mainly sourced from variation at a baseline level of blood creatinine.

\begin{tabular}{|c|c|c|c|c|c|c|c|c|c|c|}
\hline \multirow[b]{2}{*}{ Study or Subgroup } & \multicolumn{3}{|c|}{ Experimental } & \multicolumn{3}{|c|}{ Control } & & \multirow{2}{*}{$\begin{array}{l}\text { Mean Difference } \\
\text { IV. Random. } 95 \% \mathrm{Cl}\end{array}$} & \multirow{2}{*}{\multicolumn{2}{|c|}{$\begin{array}{l}\text { Mean Difference } \\
\text { IV. Random. } 95 \% \mathrm{Cl}\end{array}$}} \\
\hline & Mean & SD & Total & Mean & SD & Total & Weight & & & \\
\hline Chen2009 & 0.98 & 0.64 & 60 & 1.59 & 0.87 & 59 & $14.7 \%$ & $-0.61[-0.88,-0.34]$ & 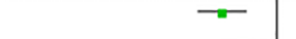 & \\
\hline Gao2012 & 1.32 & 0.8 & 40 & 1.7 & 0.9 & 40 & $13.7 \%$ & $-0.38[-0.75,-0.01]$ & & \\
\hline Kong2013 & 1.01 & 0.67 & 30 & 2.47 & 0.73 & 30 & $13.9 \%$ & $-1.46[-1.81,-1.11]$ & & \\
\hline Li2020 & 0.45 & 0.12 & 40 & 1.12 & 0.34 & 40 & $15.9 \%$ & $-0.67[-0.78,-0.56]$ & $=$ & \\
\hline WeiW2018 & 1.08 & 0.76 & 20 & 2.13 & 0.67 & 20 & $12.8 \%$ & $-1.05[-1.49,-0.61]$ & - & \\
\hline Yu2011 & 1.02 & 0.67 & 65 & 1.49 & 0.91 & 64 & $14.7 \%$ & $-0.47[-0.75,-0.19]$ & $\rightarrow$ & \\
\hline Zhou2019 & 1.8 & 1.2 & 100 & 3.6 & 1 & 100 & $14.4 \%$ & $-1.80[-2.11,-1.49]$ & - & \\
\hline Total $(95 \% \mathrm{Cl})$ & & & 355 & & & 353 & $100.0 \%$ & $-0.91[-1.27,-0.56]$ & & \\
\hline $\begin{array}{l}\text { Heterogeneity: } \mathrm{Tau}^{2}= \\
\text { Test for overall effect: }\end{array}$ & $\begin{array}{l}0.20 ; C h \\
Z=5.07\end{array}$ & $\begin{array}{l}\mathrm{h}^{2}=72 \\
(\mathrm{P}<0 .\end{array}$ & $\begin{array}{l}64, \mathrm{df}= \\
00001)\end{array}$ & $=6(P<$ & $<0.000$ & 01); $1^{2}$ & $=92 \%$ & & $\begin{array}{ccc}-2 & -1 & 0\end{array}$ & $\begin{array}{cr}1 & 2 \\
\text { Favours [control] }\end{array}$ \\
\hline
\end{tabular}




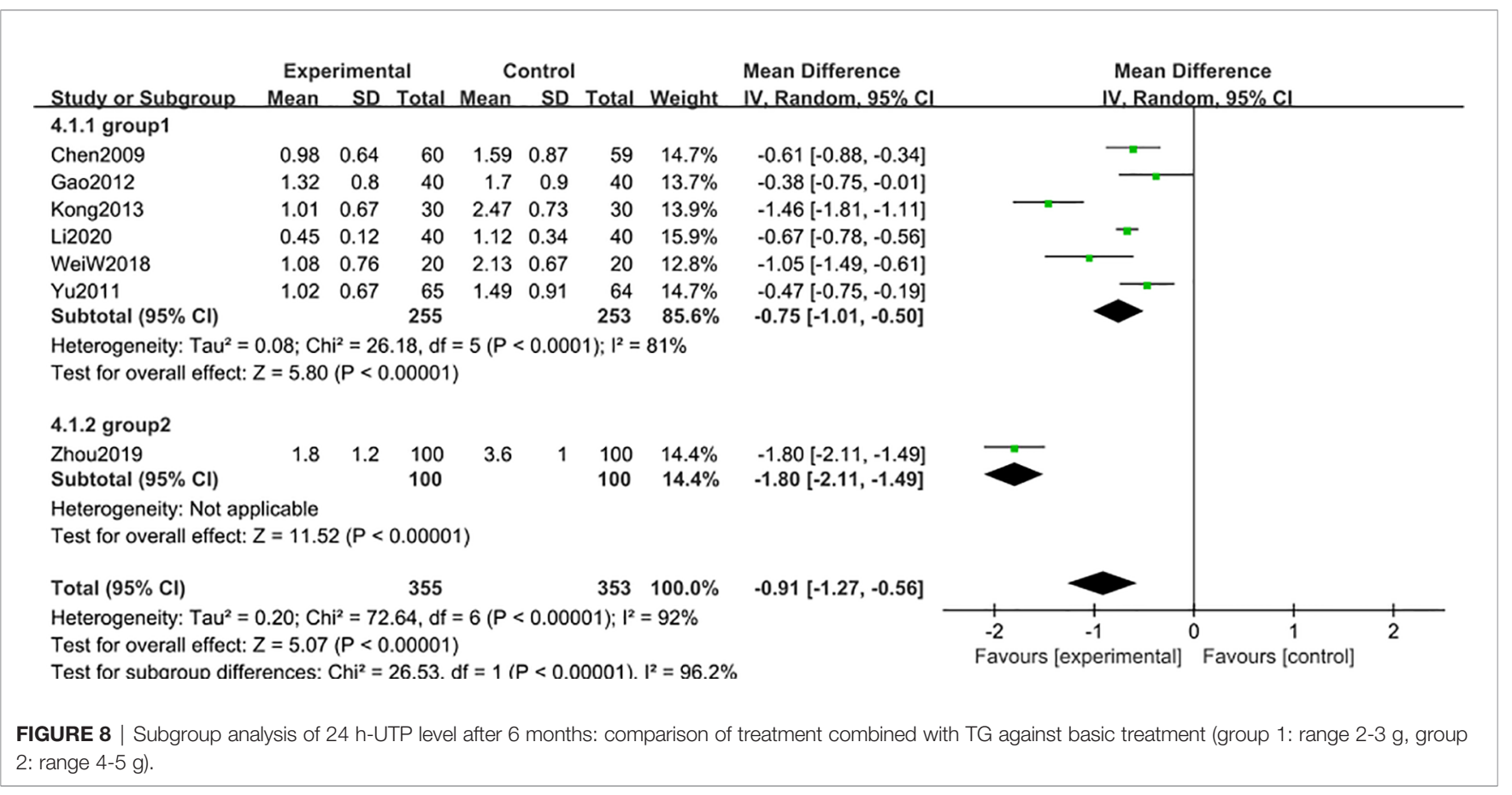

\section{Adverse Reactions}

Eleven studies (22, 48-52, 54-58) including 1032 participants, reported the adverse reaction events after 6-month of treatment combined with TG. Compared with the regular treatment, TG treatment could significantly increase the adverse reaction events [MD 3.49; 95\% CI: 1.96 to $6.22 ; \mathrm{I}^{2}=0 \%$ ] (Figure 11). The results revealed that AEs after 6 months of TG treatment were mainly manifested as symptoms of leukopenia and abnormal liver functions, further confirming the results from the previous studies that long-term use of TG could lead to liver injury and leukopenia (Table 3).

\section{GRADE Assessment}

According to the Grading of Recommendations Assessment, Development, and Evaluation (GRADE), the quality of evidence for AE was moderate, while for $24 \mathrm{~h}$-UTP and blood creatinine indicators were low (Table 4). Although the literature quality was not sufficiently high in this meta-analysis, however, a great number of participants were included in this study. This meta-analysis and systematic literature review, therefore, suggest that long-term application of TG could reduce the $24 \mathrm{~h}$-UTP and blood creatinine level of patients with $\mathrm{DN}$ to normal levels, but at the same time, it can also induce considerable AEs, further complicating DN pathogenesis.

\section{DISCUSSION}

Supplement to Compendium of Materia Medica, an ancient traditional Chinese medical book authored by Zhao Xuemin

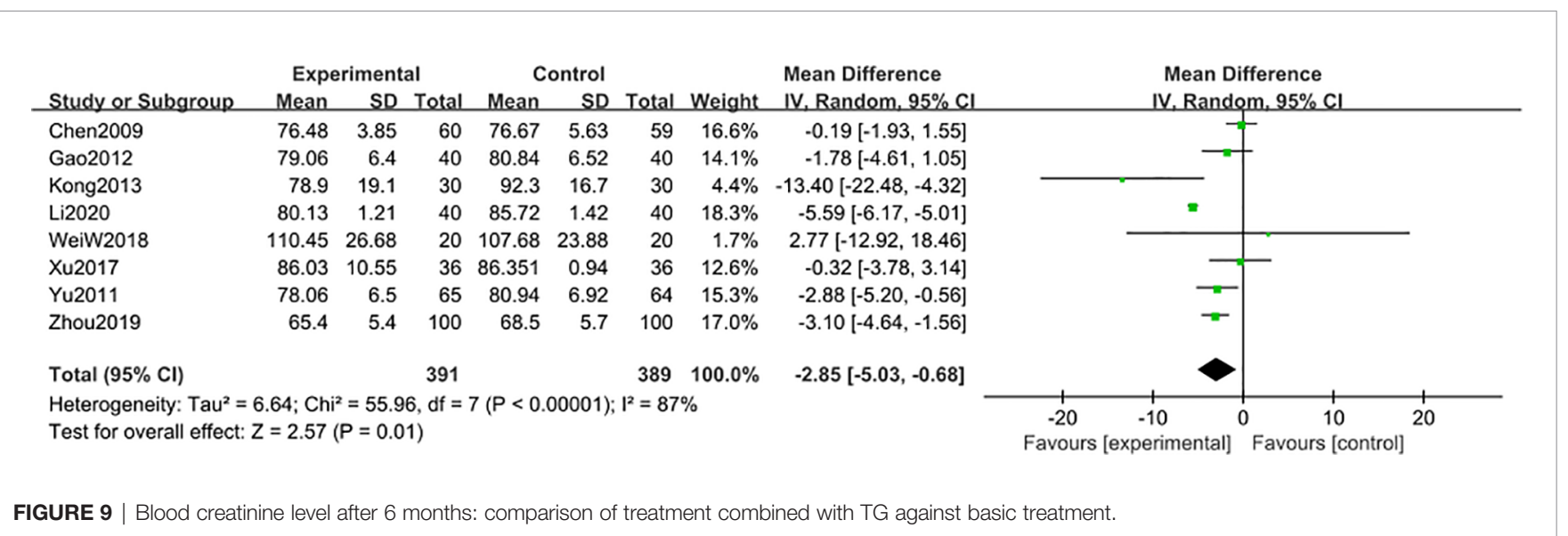




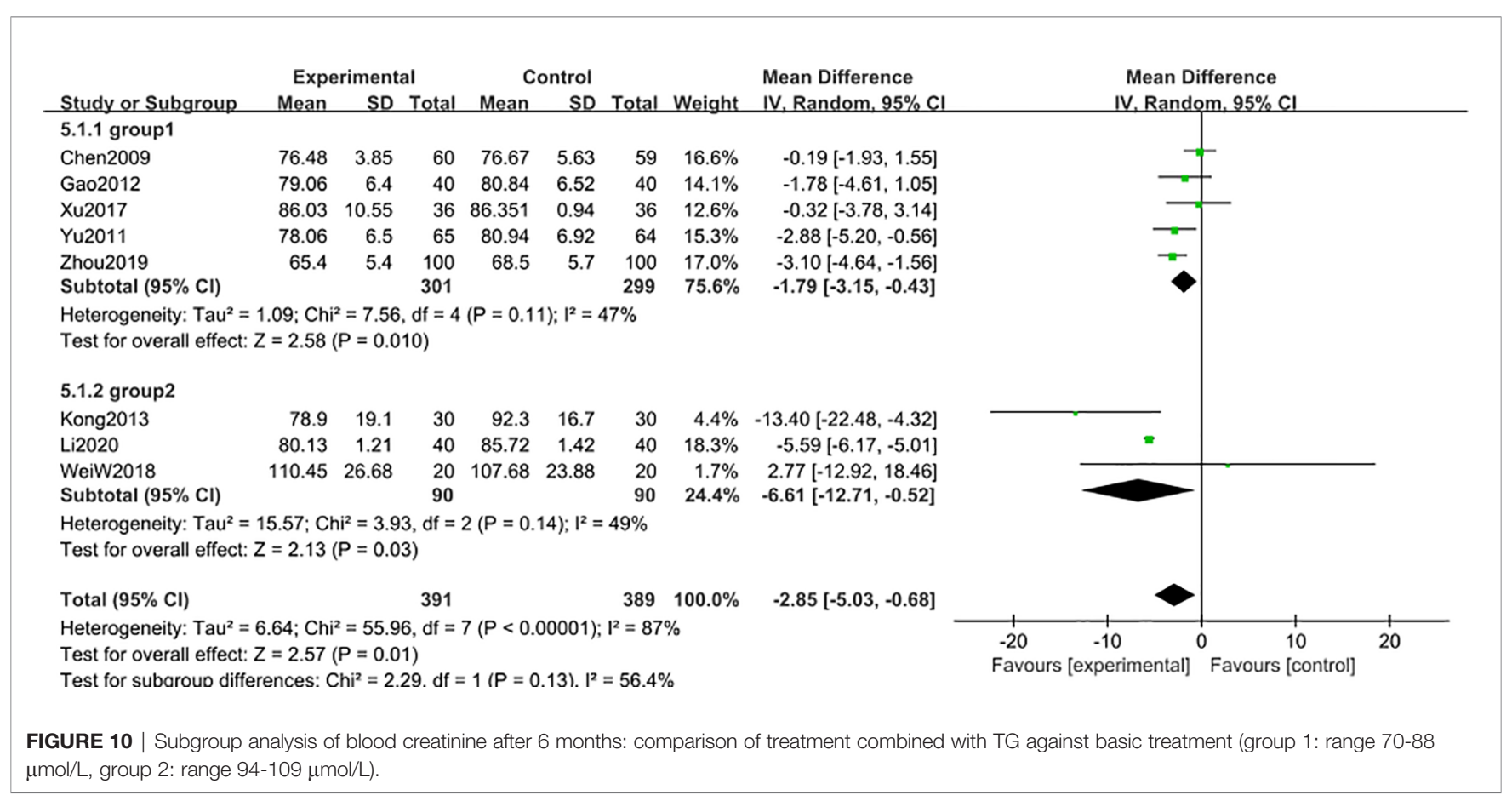

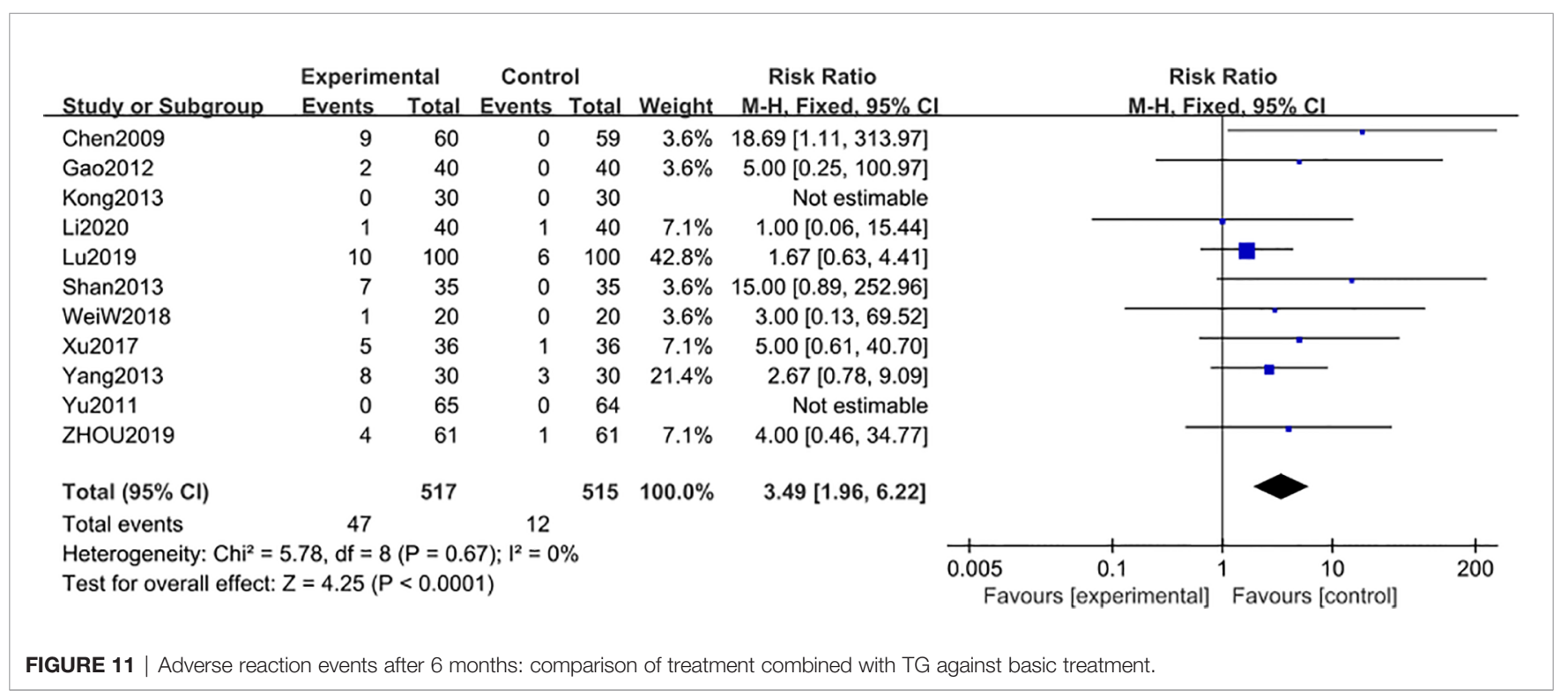

(Qing dynasty) has documented that TW can be used in the treatment of tympanites, edema, epigastric fullness, jaundice, malaria that persists for a long time and also in traumatic injury (59), indicating that TW has been used as a critical traditional medicine in treating several fatal diseases for centuries. Notably, the possible toxicities of TW administration were also recorded at the beginning of its clinical applications (60).

In recent years, the active ingredient of TW extract, TG, has been purified and subsequently tested for its toxicity. Emerging studies have shown that TG could significantly lower the levels of $24 \mathrm{~h}$-UTP and blood creatinine even in patients with the high initial baseline values, while the degree of reduction was smaller in patients with the lower initial baseline values, suggesting that TG may have a better efficacy for severe DN patients. Thus, though toxic, TG has still been used in clinical practice.

Studies on the long-term treatment effect show that after applying TG for DN 12 months, the 24 h-UTP of the patients were still significantly decreased (61). But the amount of relevant literature is insufficient to be included in this system reviews.

To maintain the balance between efficacy and safety profiles of TG usage, special attention should be paid to the appropriate dosage and duration of treatment course precisely depending on 
TABLE 3 | Statistics of adverse reaction events after 6-month treatment.

\begin{tabular}{lcc}
\hline $\begin{array}{l}\text { adverse } \\
\text { reactionevents }\end{array}$ & $\begin{array}{c}\text { treatment combined with } \\
\text { TGtotal (517 patients) }\end{array}$ & $\begin{array}{c}\text { basic treatmenttotal } \\
\text { (515 patients) }\end{array}$ \\
\hline $\begin{array}{l}\text { gastrointestinal } \\
\text { reactions }\end{array}$ & $4(0.8 \%)$ & $2(0.4 \%)$ \\
$\begin{array}{l}\text { leukopenia } \\
\text { abnormal liver } \\
\text { enzymes } \\
\text { hypoglycemia } \\
\text { elevated } \\
\text { creatinine } \\
\text { hyperkalemia } \\
\text { menstrual } \\
\text { disorders }\end{array}$ & $14(2.7 \%)^{\star}$ & $0(0.0 \%)$ \\
total & $25(4.8 \%)^{\star}$ & $0(0.0 \%)$ \\
\hline
\end{tabular}

${ }^{*} p<0.01$ (compared with basic treatment).

the pathological symptoms of individual patients. Unfortunately, comprehensive and high-quality studies are still lacking for accurate clinical application of this important drug leading to controversial medicine guidance, clinical practice and random occurrences of adverse reactions. Although the medicine guidance recommends the course of treatment with TG should not be more than 3 continuous months, however, in several clinical investigations, patients have reportedly undertaken TG treatment for up to 6 continuous months.

Our results show that though AE profiles were very similar between 3-month and 6-month of course duration, the occurrences of severe AEs were relatively much higher after 6 months. Moreover, even after 3 months of TG treatment, severe AEs can happen at a rate as high as $5.4 \%$ of total patients, suggesting that better safety can be achieved by reducing the course duration even less than 3 continuous months. To our regret, there are not enough eligible research studies available on AE occurrence in relation to the duration of treatment with TG to allow us to comprehensively investigate the cause-effect relationship. Despite this, our work could still reveal that the published guidelines on the course of treatment with TG from both medicine guidance and clinical practice should be ameliorated, and more attention should be paid to the severe AEs related to TG medication, and symptomatic treatment should be applied immediately at the onset of these severe AE symptoms.

TW contains over 400 active ingredients. As an active ingredient of TW extract, TG's combination is simplified to a series of glycosides, which decrease the toxicity, but still lack of accurate pharmacological properties and manufactural quality. At present, the standard and proportion of TG in the market are lack of consistency, so the chemical composition produced by different manufacturers may be different (62). This may also contribute to the adverse reactions of TG.

In the absence of high-quality evidence for TG-associated adverse reactions, theories of traditional Chinese medicine practice stating that 'Stabilize that condition without excessive medical treatment' could be employed to adjust the appropriate dosage of TG, while the combination with herbal extracts containing leukocyte proliferation agents, e.g., Cordyceps sinensis (63), Ganoderma lucidum (64) and liver-protecting medicine, e.g., Milk thistle (65), Polyporus umbellatus (66) extracts may be an alternative therapeutic approach to alleviate AEs and improve the safety profile of TG application.

Taken together, this meta-analysis and systematic review suggest that more comprehensive and high-quality clinical investigations are urgently warranted to establish the treatment guidelines for TG and its related adverse reactions with respect to the patient's clinical stage of DN progression as well as comorbid symptoms to broaden the therapeutic application of this important natural medicine.

To further investigate the balance of efficacy and adverse effects, firstly, we would consider analyzing the differences among more course subgroups of $\mathrm{DN}$ patients and the relationships among clinical efficacy, AEs, and individual difference. Researchers should regulate the dosage, identify the manufacturers, and focus on the relationship between the duration treatment and AEs. Secondly, more clinical endpoints should be considered to evaluate the efficacy of TG, like Glomerular filtration rate (GFR).

From a real-world research perspective, investigators also need pay attention to the standard of randomization methods, blinding, and allocation concealment to standardize RCTs. At the same time, negative results should be properly reported to avoid publication bias. Further controlled studies should be done

TABLE 4 | GRADE assessment of quality of evidence for outcomes.

\begin{tabular}{|c|c|c|c|c|c|c|c|c|c|}
\hline $\begin{array}{l}\text { Duration } \\
\text { (months) }\end{array}$ & Outcomes & Participants & studies & $\begin{array}{l}\text { Risk of } \\
\text { bias }\end{array}$ & Inconsistency & Indirectness & Imprecision & $\begin{array}{l}\text { Publication } \\
\text { bias }\end{array}$ & Overall quality of evidence \\
\hline 3 & 24h-UTP & 1120 & 14 & Serious $^{1}$ & No serious & NO serious & NO serious & Serious $^{2}$ & $\begin{array}{l}\mathrm{LOW}^{1,2} \text {, due to risk of bias, } \\
\text { publication bias }\end{array}$ \\
\hline 3 & $\begin{array}{l}\text { blood } \\
\text { creatinine }\end{array}$ & 1002 & 12 & Serious $^{1}$ & No serious & $\mathrm{NO}$ serious & NO serious & Serious $^{2}$ & $\begin{array}{l}\mathrm{LOW}^{1,2} \text {, due to risk of bias, } \\
\text { publication bias }\end{array}$ \\
\hline 3 & AR & 1148 & 13 & Serious $^{1}$ & No serious & NO serious & NO serious & NO serious & MODERATE ${ }^{1}$, due to risk of bias \\
\hline 6 & 24h-UTP & 708 & 7 & Serious $^{1}$ & No serious & NO serious & NO serious & Serious $^{2}$ & $\begin{array}{l}\mathrm{LOW}^{1,2} \text {, due to risk of bias, } \\
\text { publication bias }\end{array}$ \\
\hline 6 & $\begin{array}{l}\text { blood } \\
\text { creatinine }\end{array}$ & 780 & 8 & Serious $^{1}$ & No serious & NO serious & NO serious & Serious $^{2}$ & $\begin{array}{l}\mathrm{LOW}^{1,2} \text {, due to risk of bias, } \\
\text { publication bias }\end{array}$ \\
\hline 6 & $\mathrm{AR}$ & 1032 & 11 & Serious $^{1}$ & No serious & NO serious & NO serious & NO serious & MODERATE ${ }^{1}$, due to risk of bias \\
\hline
\end{tabular}

1.The random and blind methods were of poor quality. 2. There was publication bias. 
on the age, stage, course of DN patients to evaluate what difference is made in the efficacy of TG for different populations.

\section{LIMITATIONS}

This study also suffers from certain inevitable limitations that require further consideration. Firstly, and most importantly, publications on the $24 \mathrm{~h}$-UTP and blood creatinine indices after 3 -month course of treatment with TG are significantly biased. And secondly, high-quality research studies relating to TG dosage and induced adverse reactions are not enough to firmly conclude on specific AEs due to particular TG treatment course.

Furthermore, most of the systematic reviews focused on efficacy or effectiveness. The methodology for conducting systematic reviews of beneficial effects from RCTs is well established, whereas the methods for systematically reviewing randomized or observational data on AEs are less well developed and less often used (67). Thus, researchers who conduct systematic reviews have limited sources of guidance, such as the suggestions offered by the Cochrane Collaboration. Moreover, the pre-determined harmful effects of interest were known to be under-reported in RCTs (68). These questions lead us to some innate limitations in this systematic review.

Although some researchers are accustomed to using $24 \mathrm{~h}-$ UTP and blood creatinine as the main surrogate biomarkers to evaluate the prognosis of renal disease in RCTs, 24 h-UTP and blood creatinine still have great limitations as clinical endpoint.

Because of the kidney's ability of compensate, when patients with renal impairment, the blood creatinine may still be in a normal level. Blood creatinine and $24 \mathrm{~h}$-UTP does not reflect the long-time state of renal function well, so risks would be produced by using them to determine the efficacy. GFR is a better indicator for evaluating renal function. But, GFR is rarely used in clinical studies to evaluate the efficacy of TG. Recently, a growing number of studies have shown that the sensitivity of cystatin $C$ to the decrease of GFR is better than that of blood creatinine, especially in the early stage of renal injury (69-71). Unfortunately, cystatin C is not widely applied at present, and relevant literature remain scarce. Our understanding of DN may greatly benefit from more detailed investigation into these surrogate indicators.

\section{CONCLUSION}

Our results have revealed that symptomatic treatments combined with TG can significantly lower $24 \mathrm{~h}$-UTP and blood creatinine levels in DN patients than the basic treatment without TG can do, confirming the efficacy of TG. While forest plots of these two indicators have exhibited that apparent heterogeneity remains even after subgroup and sensitivity analyses, however, there are ways to reduce the heterogeneity to an acceptable degree.

Regarding the induction of adverse side-effects, patients from both 3-month and 6-month groups undertaking TG medications showed critical $\mathrm{AE}$ onsets, e.g. leukopenia and abnormal liver functions, especially more aggressively in patients of the 6-month treatment group. However, these results were inconsistent with the published reports we included in this study, indicating no significant differences in $\mathrm{AE}$ profiles between the experimental group and placebo-treated or control group. According to the GRADE assessments, the quality of evidence from these articles was low, primarily might be due to the insufficient sample size and errorprone experimental designs. Thus, the descriptions of AEs from the medicine guidance should be really concerning in clinical practice.

Importantly, the occurrence of AEs was very similar after 3month $(64 / 574,11.1 \%)$ and 6-month $(47 / 517,9.1 \%)$ of TG treatment durations. However, the incidence of severe AEs after 6-month treatment with TG $(39 / 517,7.5 \%)$ reportedly had 39\% increment than that happened after 3-month treatment with TG $(31 / 574,5.4 \%)$. The total percent of AEs in treatment with TG didn't greatly increase with TG, but as the course of treatment lasted, severe AEs were more likely to happen.

In summary, our work showed that TG was therapeutically effective in the treatment of DN-related symptoms like proteinuria, high serum creatinine, but insufficient sample sizes and inappropriate experimental designs caused non-significant $\mathrm{AE}$ differences between the experimental and control groups in several studies. AE occurrence rate was found nearly constant as the medicine duration increased, however, the percent of severe AEs after 6 months of treatment was 1.39 times more than that after 3 months.

\section{DATA AVAILABILITY STATEMENT}

The original contributions presented in the study are included in the article/Supplementary Material. Further inquiries can be directed to the corresponding authors.

\section{AUTHOR CONTRIBUTIONS}

YLi and RM wrote the manuscript. YLi and RM selected the trials. ZD and JZ extracted the data. YZ and LZ assessed the quality of the studies. $\mathrm{ZH}$ and $\mathrm{YZ}$ assessed the quality of the evidence. YLiu, PM, and YLi performed the statistical analysis. $\mathrm{DH}$ and YX conceived of the study, and all other authors critically reviewed the report. All authors contributed to the article and approved the submitted version.

\section{FUNDING}

National Key R\&D Program of China, No. 2019YFC1709801.

\section{SUPPLEMENTARY MATERIAL}

The Supplementary Material for this article can be found online at: https://www.frontiersin.org/articles/10.3389/fendo.2021. 656621/full\#supplementary-material 


\section{REFERENCES}

1. Care F. Standards of Medical Care in Diabetes 2019. Diabetes Care (2019) 42 (Suppl 1):S124-38. doi: 10.2337/dc19-S011

2. Saran R, Robinson B, Abbott KC, Agodoa LYC, Ayanian J, Gresham JB, et al. US Renal Data System 2018 Annual Data Report: Epidemiology of Kidney Disease in the United States. Am J Kidney Dis (2019) 71(3):A7-8. doi: 10.1053/j.ajkd.2016.12.004

3. Brenner BM, Cooper ME, Zeeuw D, Keane WF, Mitch WE, Parving HH, et al. Effects of losartan on renal and cardiovascular outcomes in patients with type 2 diabetes and nephropathy. $N$ Engl J Med (2001) 345(12):861-9. doi: 10.1056/NEJMoa011161

4. Lin YC, Chang YH, Yang SY, Wu KD, Chu TS. Update of pathophysiology and management of diabetic kidney disease. J Formos Med Assoc (2018) 117 (8):662-75. doi: 10.1016/j.jfma.2018.02.007

5. Ye H, Huo Z, Ye P, Xiao G, Zhang Z, Xie C, et al. Comparative proteinuria management of different angiotensin-converting enzyme inhibitors or angiotensin receptor blockers for normotensive patients with CKD: a Bayesian network meta-analysis. Peer J (2020) 8:e8575. doi: 10.7717/ peerj. 8575

6. Xu R, Sun S, Huo Y, Yun L, Huang S, Li GH, et al. Effects of ACEIs versus ARBs on proteinuria or albuminuria in primary hypertension: a meta-analysis of randomized trials. Medicine (2015) 94(39):e1560. doi: 10.1097/ MD.0000000000001560

7. Hou FF, Zhang X, Zhang GH, Xie D, Chen PY, Zhang WR, et al. Efficacy and safety of benazepril for advanced chronic renal insufficiency. N Engl J Med (2006) 354(2):131-40. doi: 10.1056/NEJMoa053107

8. Dungey M, Hull KL, Smith AC, Burton JO, Bishop NC. Inflammatory factors and exercise in chronic kidney disease. Int J Endocrinol (2013) 2013:569831. doi: 10.1155/2013/569831

9. Sulaiman MK. Diabetic nephropathy: recent advances in pathophysiology and challenges in dietary management. Diabetol Metab Syndr (2019) 11(1):7. doi: 10.1186/s13098-019-0403-4

10. Wada J, Makino H. Inflammation and the pathogenesis of diabetic nephropathy. Clin Sci (Lond) (2013) 124(3):139-52. doi: 10.1042/CS20120198

11. Cao Z, Cooper ME. Pathogenesis of diabetic nephropathy. J Diabetes Investig (2011) 2(4):243-7. doi: 10.1111/j.2040-1124.2011.00131.x

12. Moreno JA, Gomez-Guerrero C, Mas S, Sanz AB, Lorenzo O, Ortega MR, et al. Targeting inflammation in diabetic nephropathy: a tale of hope. Expert Opin Investig Drugs (2018) 27(11):917-30. doi: 10.1080/13543784.2018.1538352

13. Lu C, Fan G, Wang D. Akebia Saponin D ameliorated kidney injury and exerted anti-inflammatory and anti-apoptotic effects in diabetic nephropathy by activation of NRF2/HO-1 and inhibition of NF-KB pathway. Int Immunopharmacol (2020) 84:106467. doi: 10.1016/j.intimp.2020.106467

14. Kawanami D, Matoba K, Takeda Y, Nagai Y, Akamine T, Yokota T, et al. SGLT2 inhibitors as a therapeutic option for diabetic nephropathy. Int J Mol Sci (2017) 18(5):1083. doi: 10.3390/ijms18051083

15. Yao JR, Sun Y, Luo SK, Xie DH. Progress of tripterygium glycosides in clinical application. Chin J New Drugs Clin Remedies (2010) 29(03):179-82.

16. Su HJ, Qian Y, Li H, Li E. Efficacy of Tripterygium Glycosides on Proteinuria Patients with Diabetic Nephropathy. Med J Wuhan Univ (2013) 34(2):296-8.

17. Zhang YX, Liu GL, Wang JQ, Li YC. Antioxidative effect of Tripterygium wilfordii polyglycosides on diabetic rats. Chin J Pharmacol Toxicol (2014) 28 (3):358-61. doi: 10.3867/j.issn.1000-3002.2014.03.008

18. Chen ZH, Qin WS, Zeng CH, Zheng CX, Hong YM, Lu YZ, et al. Triptolide reduces proteinuria in experimental membranous nephropathy and protects against C5b-9-induced podocyte injury in vitro. Kidney Int (2010) 77 (11):974-88. doi: 10.1038/ki.2010.41

19. Xu LN, Zhao B, Wang HT, Liu LL, Chen AQ, Wang H, et al. Tripterygium wilfordii Hook F Treatment for Stage IV Diabetic Nephropathy: Protocol for a Prospective, Randomized Controlled Trial. BioMed Res Int (2020) 2020(3):19. doi: $10.1155 / 2020 / 9181037$

20. Ru Y, Luo Y, Zhou Y, Kuai L, Sun X, Xing M, et al. Adverse events associated with treatment of Tripterygium wilfordii Hook F: a quantitative evidence synthesis. Front Pharmacol (2019) 10:1250. doi: 10.3389/fphar. 2019.01250
21. Jiang M, Zha Q, Zhang C, Lu C, Yan X, Zhu W, et al. Predicting and verifying outcome of Tripterygium wilfordii Hook F. based therapy in rheumatoid arthritis: from open to double-blinded randomized trial. Sci Rep (2015) 5:9700. doi: $10.1038 /$ srep09700

22. Wang W. Different doses of Tripterygium glycosides in the treatment of diabetic nephropathy: effects on blood lipids. Kidney Blood Press Res (2018) 43 (3):931-7. doi: 10.1159/000490472

23. Ge Y, Xie H, Li S, Jin B, Hou J, Zhang H, et al. Treatment of diabetic nephropathy with Tripterygium wilfordii Hook F extract: a prospective, randomized, controlled clinical trial. J Transl Med (2013) 11(1):134 doi: 10.1186/1479-5876-11-134

24. Liang XH, Fan P. Systematic evaluation of the clinical effects of Tripterygium wilfordii multi glycoside tablets on diabetic kidney disease. J Shanxi Med University (2016) 47(08):751-5 doi: 10.13753/j.issn.1007-6611.2016.08.017

25. Fang JY, Yang Y, Zhang Z, Jiang SM, Yu TY, Li WG. Effects of adding tripterygium glycosides to angiotensin-converting enzyme inhibitors or angiotensin receptor blockers on albuminuria in patients with diabetic nephropathy. CDTM (2020) 1:18-26 doi: 10.1016/j.cdtm.2019.12.008

26. Wu X, Huang Y, Zhang Y, He CL, Zhao YL, Wang LZ, et al. Efficacy of tripterygium glycosides combined with ARB on diabetic nephropathy: a metaanalysis. Biosci Rep (2020) 40(11):1-13. doi: 10.1042/BSR20202391

27. Hong Y, Gui Z, Cai X, Lan L. Clinical efficacy and safety of tripterygium glycosides in treatment of stage IV diabetic nephropathy: A meta-analysis. Open Med (2016) 11(1):611-7. doi: 10.1515/med-2016-0099

28. Huang J, Zhang JQ, Chen Z, Zhang Y, Chen WD, Wu XP. Systematic evaluation for efficacy of tripterygium glycosides in treating diabetic nephropathy stage IV. CJCMM (2015) 40(15):3100-9.

29. Li J. Observation of the effect of Tripterygium combined with huangkui capsule in the treatment of diabetic nephropathy. Chin J Prim Med Pharm (2012) 19(18):2731-2. doi: 10.3760/cma.j.issn.1008-6706.2012.18.006

30. Lu GY. Effect of Tripterygium Glycosides combine with valsartan on blood glucose of patients with diabetic nephropathy stage IV. $J$ Med Aesthetics Cosmetol (2020) 29(13):100.

31. Wang JC. Clinical observation of Tripterygium Glycosides combined with irbesartan in the treatment of diabetic nephropathy. China Prac Med (2013) 8 (05):182-3. doi: 10.3969/j.issn.1673-7555.2013.05.131

32. Gai YL, Wang YY, Yang XC. Observation on the effect of combined use of Tripterygium Glycosides and Huangkui Capsule on diabetic nephropathy. Contemp Med Symposium (2020) 18(04):113-4.

33. Zhu $\mathrm{H}, \mathrm{Hu} \mathrm{JH}$, Bao JX. Efficacy of Huangkui Capsule combined with Tripterygium Glycosides in the treatment of stage IV diabetic nephropathy. Zhejiang Clin Med (2018) 20(9):1535-6.

34. Wang XN, Yuan XY, Zhang MZ. Effect of Tripterygium glycosides combined with alprostadil on cytokine concentration in patients with diabetic nephropathy. Chin J Clin Pharmacol (2017) 33(17):1625-7. doi: 10.13699/ j.cnki.1001-6821.2017.17.004

35. Sun LY, Wu JX, Shen SZ. Effects of Tripterygium Glycosides on Adiponectin Levels in Blood and Urine of Patients with Diabetic Nephropathy. Shenzhen J Integrated Traditional Chin Western Med (2019) 29(24):26-8. doi: 10.16458/ j.cnki.1007-0893.2019.24.012

36. Yan YC. Effects of Tripterygiun Wilfordii Extract on T Lymphocytes and Urinary Microprotein in Patients with Diabetic Nephropathy. Lingnan J Emergency Med (2017) 22(04):356-9. doi: 10.3969/j.issn.1671-301X.2017.04.019

37. Liu J, Li H, Wang H, Li T, Zhang W. Effect of Tripterygium glycosides on blood and urine MCP-1 of patients with diabetic nephropathy. China Modern Doctor (2015) 53(17):8-10.

38. Wang SQ, Wang DQ. Therapeutic effect of Tripterygium Glycosides Combined with Pancreatic Kininogenase in Treatment of Diabetic Nephropathy. J Clin Res (2018) 35(10):1902-4. doi: 10.3969/j.issn.1671-7171.2018.10.010

39. Liu JL, Chen ML, Li H, Wang HC, Zhang W. Effect of Tripterygium glycosides combined with Irbesartan on podocyte injury in diabetic nephropathy. China Modern Doctor (2015) 53(15):76-8.

40. Zhang LF. Clinical observation of Yiqi Yangyin Huoxue method combined with Tripterygium Glycosides in the treatment of diabetic nephropathy in stage IV. Henan Univ Traditional Chin Med (2015) 06:1-58.

41. Shen SJ, Hu ZX, Wang SM, Li QH. Clinical observation of Huangkui capsule combined with Tripterygium Glycosides in the treatment of stage IV diabetic nephropathy. Chin J Pharmacol Ther (2011) 16(01):85-8. 
42. Shi XY. Huangkui capsule combined with Tripterygium Glycosides in the treatment of diabetic nephropathy clinical efficacy and safety. World Latest Med Infor (2018) 18(90):101-2. doi: 10.19613/j.cnki.1671-3141.2018.90.074

43. Sun XJ. Clinical observation of the effect of Tripterygium Glycosides on proteinuria in patients with diabetic nephropathy. Nanjing Univ Chin Med (2012) 10:1-46. doi: 10.7666/d.y2124401

44. Shen WG, Yan ZQ, He ME. Efficacy of Tripterygium Glycosides in the Treatment of Diabetic Nephropathy with Peritoneal Dialysis and Mass Proteinuria. CJITWN (2011) 12(03):261-2. doi: 10.3969/j.issn.1009587X.2011.03.028

45. Hao SH, Hu HM. Clinical observation of Tripterygium Glycosides in the treatment of diabetic nephropathy with massive proteinuria. Chin Manipulation Rehabil Med (2017) 8(13):45-6. doi: 10.3969/j.issn.10081879.2017.13.021

46. Li HJ. The Clinical Efficacy of Losartan Combined with Tripterygium Glycosides in the Treatment of Diabetic Nephropathy and the Influence of Urine Microalbumin and Other Indicators. Diabetes New World (2018) 21 (24):196-8.

47. Ma AJ, Yao X. Effects of Tripterygium Wilfordii Polyglycoside Tablet combined with Natrium-Glucose Cotransporter 2 Inhibitor on Renal Function and Proteinuria in Patients with Diabetic Nephropathy. Chin Arch Traditional Chin Med (2020) 38(08):200-3. doi: 10.13193/j.issn.1673-7717.2020.08.048

48. Kong SN, Li HL, Wang HW. Treatment of senile diabetic nephropathy with Tripterygium Glycosides Tablet. Chin J Prim Med Pharm (2013) 20(24):37767. doi: $10.3760 / \mathrm{cma}$.j.issn.1008-6706.2013.24.042

49. Lu GY, Zhou GH, Geng LM, Zhao XF, Deng GX. Clinical effect observation of Tripterygium Glycosides combined with valsartan in the treatment of diabetic nephropathy stage IV. Diet Health Care (2019) 6(41):47.

50. Yu ZF. Clinical effects of Tripterygium for Diabetic Nephropathy. Med Info (2011) 24(06):2440-1. doi: 10.3969/j.issn.1006-1959.2011.06.241

51. Yang T. Clinical efficacy of Tripterygium Glycosides combined with valsartan in the treatment of early Diabetic Nephropathy. Qingdao Med J (2013) 45 (04):270-1. doi: 10.3969/j.issn.1006-5571.2013.04.014

52. Li LC. Analysis and study on the effect of tripterygium glycoside tablets in the treatment of diabetic nephropathy proteinuria. Chin Community Doctors (2020) 36(05):56-7. doi: 10.3969/j.issn.1007-614x.2020.05.035

53. Zhou GH, Lu GY, Geng LM, Zhao XF. Efficacy of Tripterygium Glycosides combined with valsartan in the treatment of Diabetic Nephropathy (DN) stage IV and the effect on renal function of patients. Diet Health Care (2019) 6 (40):43-4.

54. Xu GB, Chen DJ, Chen WZ. Effect of Tripterygium Wilfordii Polyglycoside on Inflammatory Factor Level in Patients with Diabetic Nephropathy. Chin Arch Traditional Chin Med (2017) 35(08):2206-8. doi: 10.13193/j.issn.16737717.2017.08.079

55. Gao SP. Randomized controlled trial of Tripterygium Glycosides in the treatment of diabetic nephropathy. Hainan Med J (2012) 23(14):31-2. doi: 10.3969/j.issn.1003-6350.2012.14.012

56. Chen QN, Zhou ZQ, Xie AY. Clinical observation of Tripterygium Glycosides in the treatment of diabetic nephropathy. CJITWN (2009) 10(8):717-8. doi: 10.3969/j.issn.1009-587X.2009.08.018

57. Shan JP, Wang SM, Guan JC. Clinical observation of Tripterygium Glycosides combined with Bailing in the treatment of early Diabetic Nephropathy. CJITWN (2013) 14(01):58-9. doi: 10.3969/j.issn.1009-587X.2013.01.019

58. Zhou HZ. Effect of tripterygium glycosides on clinical efficacy and inflammatory factors in patients with Diabetic Nephropathy. Chronic
Pathematology J (2019) 20(09):1346-8. doi: 10.16440/j.cnki.16748166.2019.09.023

59. Zhao XM. Supplement to Compendium of Materia Medica Vol. 233. . Beijing: China Traditional Chinese Medicine Press (1998).

60. Li SZ. Compendium of Materia Medica Vol. 86. Wuhan: Chongwen Publishing House (2015).

61. Zhang HC. Tripterygium wilfordii polyglycoside tablets in the adjuvant treatment of 66 cases of diabetic nephropathy stage IV. China Pharm (2015) 24(024):248-9.

62. Liu WC, Wang SC, Tsai ML, Chen MC, Wang YC, Hong JH, et al. Protection against Radiation-Induced Bone Marrow and Intestinal Injuries by Cordyceps sinensis, a Chinese Herbal Medicine. Radiat Res (2006) 166(6):900-7. doi: $10.1667 /$ RR0670.1

63. He Y, Shi SL, Zhang RP, Qian JJ, Fan YS. Determination of main effective components in tripterygium glycosides. CJPA (2013) 33(02):197-200.

64. Zhu XL, Chen AF, Lin ZB. Ganoderma lucidum polysaccharides enhance the function of immunological effector cells in immunosuppressed mice. J Ethnopharmacol (2007) 111(2):219-26. doi: 10.1016/j.jep.2006. 11.013

65. McBride A, Augustin KM, Nobbe J, Westervelt P. Silybum marianum (milk thistle) in the management and prevention of hepatotoxicity in a patient undergoing reinduction therapy for acute myelogenous leukemia. J Oncol Pharm Prac (2012) 18(3):360-5. doi: 10.1177/1078155212438252

66. Guo Z, Zang Y, Zhang L. The efficacy of Polyporus Umbellatus polysaccharide in treating hepatitis B in China. Prog Mol Biol Transl Sci (2019) 163:329-60. doi: 10.1016/bs.pmbts.2019.03.012

67. Mcintosh HM, Woolacott NF, Bagnall AM. Assessing harmful effects in systematic Reviews. BMC Med Res Methodol (2004) 4(1 Supplement):19-9. doi: 10.1186/1471-2288-4-19

68. Loke YK, Derry S. Incorporating adverse effects data into reviews: how to get started [abstract]. In: 9th Annual Meeting for UK Contributors to the Cochrane Collaboration. Coventry (2003).

69. Shlipak MG, Matsushita K, Ärnlöv J, Inker LA, Katz R, Polkinghorne KR, et al. Cystatin $\mathrm{C}$ versus creatinine in determining risk based on kidney function. NEJM (2013) 369(10):932-43. doi: 10.1056/NEJMoa1214234

70. Dharnidharka VR, Kwon C, Stevens G. Serum cystatin C is superior to serum creatinine as a marker of kidney function: a meta-analysis. Am J Kidney Dis (2002) 40(2):221-6. doi: 10.1053/ajkd.2002.34487

71. Peralta CA, Shlipak MG, Judd S, Cushman M, McClellan W, Zakai NA, et al. Detection of chronic kidney disease with creatinine, cystatin $\mathrm{C}$, and urine albumin-to-creatinine ratio and association with progression to end-stage renal disease and mortality. Jama (2011) 305(15):1545-52. doi: 10.1001/ jama.2011.468

Conflict of Interest: The authors declare that the research was conducted in the absence of any commercial or financial relationships that could be construed as a potential conflict of interest

Copyright $\odot 2021$ Li, Miao, Liu, Zhang, Dou, Zhao, Zhang, Huang, Xia and Han. This is an open-access article distributed under the terms of the Creative Commons Attribution License (CC BY). The use, distribution or reproduction in other forums is permitted, provided the original author(s) and the copyright owner(s) are credited and that the original publication in this journal is cited, in accordance with accepted academic practice. No use, distribution or reproduction is permitted which does not comply with these terms. 